\title{
Desarrollo inmobiliario y gobiernos locales en la periferia de la Ciudad de México
}

\section{Georgina Isunza Vizuet \\ Benjamin Méndez Babena}

Profesores-Investigadores del Centro de Investigaciones Económicas, Administrativas y Sociales (CIECAS) del Instituto Politécnico Nacional (IPN), México.

RESUMEN | La nueva modalidad de urbanización caracterizada por la construcción de conjuntos habitacionales de gran escala en la periferia de las ciudades ha provocado un impacto en los gobiernos locales, cuya reducida capacidad de gestión, limitadas competencias y escaso presupuesto se expresa en la incapacidad de proporcionar servicios básicos a su población. Una mirada a seis municipios de la Zona Metropolitana del Valle de México permite examinar cómo el centralismo exacerba este fenómeno.

PALABRAS CLAVE | Gobierno local, mercado inmobiliario, política habitacional

ABSTRACT | The new form of urbanization characterized by the construction of large scale housing developments on the outskirts of cities has caused an impact on local governments, whose reduced management capacity, limited skills and limited budget is expressed in the inability to provide basic services to population. A look at six municipalities of the Metropolitan Area of Mexico City, let's examine how the centralization exacerbates this phenomenon.

KEY WORDS | Local government, real state market, housing policy

Recibido el 24 de marzo de 2010, aprobado el 9 de diciembre de 2010.

Correspondencia: Lauro Aguirre No. 120 Col. Agricultura, Delegación Miguel Hidalgo, México, D. F. 11360. Teléfono 57296300 ext.63115, fax 53969507. E-mail: ginaisunza@yahoo.com.mx | bmendezb@hotmail.com 


\section{Introducción}

Como en otras regiones del planeta, en México un rasgo distintivo del proceso de urbanización es el acelerado crecimiento en el tamaño y número de las zonas metropolitanas. Un estudio oficial contabilizó 56 en el año 2005, que concentraban 56\% de la población del país y 75\% del Producto Interno Bruto (SEDESOLCONAPO-INEGI, 2005, pp. 9-10). Entre ellas sobresale la Zona Metropolitana del Valle de México, cabeza del sistema urbano nacional, en donde residían 19 millones 239 mil 910 habitantes en 2005 , equivalentes a $18,6 \%$ de la población nacional (INEGI, 2005). La Figura 1 ubica a la ZMVM en el territorio nacional.

\section{FIGURA 1 | Ubicación de la Zona Metropolitana del Valle de México}

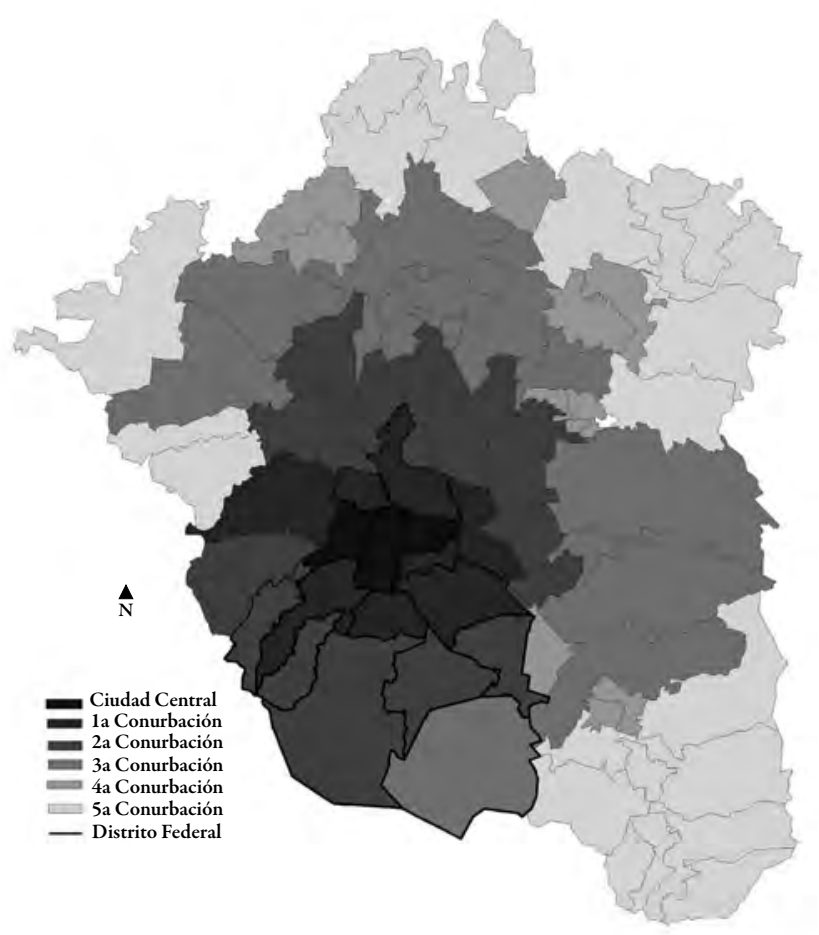

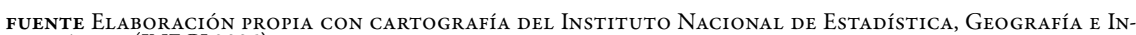
FORMÁTICA (INEGI 2005).

A pesar de su importancia económica, demográfica y potencialidad como factor de desarrollo económico, las zonas metropolitanas mexicanas carecen de instrumentos vinculantes para realizar una eficaz gestión urbana (SEDESOLCONAPO-INEGI, 2005, pp. 9-10). Un ejemplo es la periferia de la Zona Metropolitana del Valle de México $(\mathrm{ZMVM})^{1}$ donde desde principios del siglo

1 Incluye 16 delegaciones del Distrito Federal, 58 municipios del Estado de México y un municipio del Estado de Hidalgo, según la delimitación de la Secretaría de Desarrollo Social (SEDESOL), el Consejo Nacional de Población (CONAPO) y el INEGI, 2005. 
XXI algunos municipios se han convertido en receptores de grandes conjuntos habitacionales, construidos por promotores privados pero financiados conjuntamente por organismos públicos de vivienda y créditos hipotecarios otorgados con elevadas tasas de interés por bancos privados. Ello ha dotado de nuevos rasgos al proceso de urbanización, como la conformación de núcleos de población fragmentados, desintegrados funcional y socialmente con las formas de poblamiento preexistentes. Ahí los gobiernos municipales enfrentan grandes desafíos para proporcionar servicios tanto a la nueva población, que proviene principalmente de las áreas centrales e intermedias de la Ciudad de México, como a los viejos residentes, originando un desfase entre las competencias de gobierno en el nivel local, con las nuevas, crecientes y diversificadas necesidades de la población. Adicionalmente, los gobiernos municipales son incapaces de promover arreglos institucionales entre los distintos niveles de gobierno ${ }^{2}$ que confluyen en el espacio metropolitano ${ }^{3}$, poniendo en evidencia sus escasas posibilidades de enfrentar los efectos más perniciosos de esta modalidad de expansión urbana. Para establecer la zona de estudio, la Figura 2 presenta la ZMVM, indicando cinco etapas de su conurbación.

\section{FIGURA 2 | Zona Metropolitana del Valle de México. Contornos Metropolitanos y} municipios de estudio

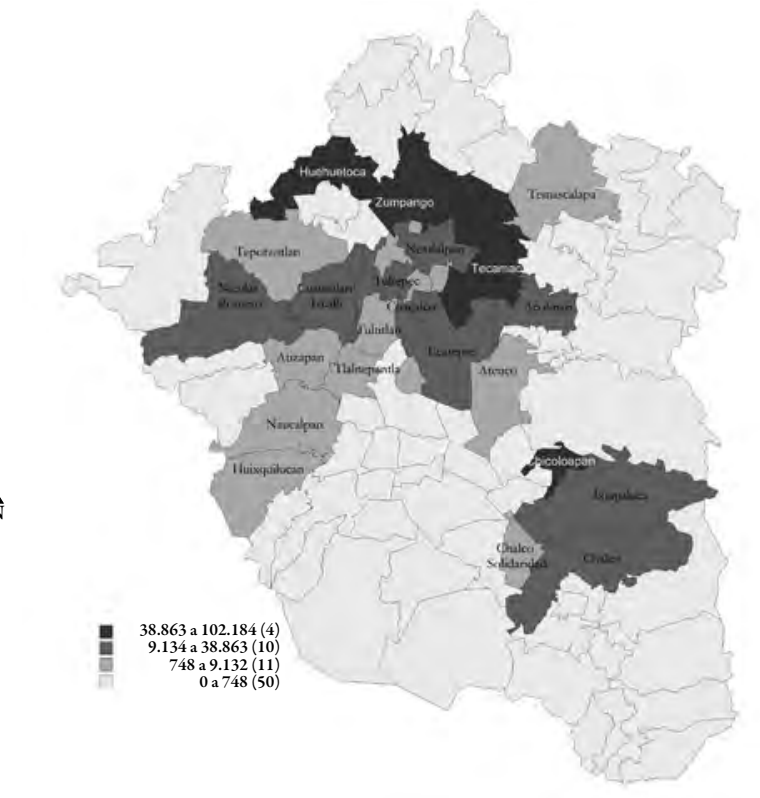

FUENTE Elaboración propia CON CARTOGRafía del InStituto NaCional de Estadística, Geografía e InFORMÁTICA (INEGI 2005).

2 Gobierno Federal o nacional; gobiernos estatales o subnacionales y gobiernos municipales o locales.

3 Según los artículos 40, 43 y 115 de la Constitución Política, los Estados Unidos Mexicanos son una República compuesta por 31 estados libres y soberanos unidos en una federación, más un Distrito Federal en donde reside la capital del país. Los estados se dividen en municipios y el Distrito Federal en Delegaciones Políticas. 
Si bien la política de vivienda tiene un carácter federal (nacional), sus repercusiones más notables suceden en los espacios locales, en especial en aquellas zonas metropolitanas que comprenden espacios de gobierno complejos, debido a que el funcionamiento del mercado inmobiliario involucra a tres niveles de gobierno. Como un caso peculiar, en la ZMVM operan cinco gobiernos diferentes: el federal, tres subnacionales (Distrito Federal, Estado de México y Estado de Hidalgo) y el gobierno local, que en los estados de México e Hidalgo es el municipio, en tanto en el Distrito Federal existen órganos político-administrativos llamados delegaciones con menores competencias que un municipio (Congreso de la Unión, 1917, art. 115 y Gaceta Oficial del Distrito Federa, 1994, art. 117).

En este escenario, el análisis de la capacidad de gestión de los gobiernos municipales en el Estado de México pasa por definir las competencias que los instrumentos vinculantes les confieren -particularmente en urbanización y finanzas, áreas en donde los gobiernos locales pueden intervenir- y cómo están facultados para ponerlas en práctica, estableciendo así los alcances y los límites de su actuación, para posteriormente examinar en qué medida cumplen con sus funciones y si éstas son las adecuadas.

$\mathrm{Al}$ efecto, se adopta en este trabajo la idea de que la gestión pública es el conjunto sistematizado de prácticas de un gobierno, que orientadas a promover los objetivos de desarrollo definidos por su comunidad, articulan el ejercicio de sus atribuciones establecidas en la legislación vigente en ese territorio, promueven la incorporación de otros actores públicos o privados a tareas específicas, organizan los recursos presupuestales, humanos y tecnológicos asignados a sus agencias, fomentando la innovación, así como impulsando la participación organizada y supervisión de la sociedad civil.

\section{Desarrollo inmobiliario: tendencias globales, impactos locales}

El comportamiento actual del mercado inmobiliario en diversas naciones tiene como telón de fondo la crisis financiera-inmobiliaria que estalla a mediados del año 2007 en Estados Unidos. Ella constituye el primer signo del riesgo implicado en el abuso de instrumentos financieros, porque finalmente esta crisis de deuda está precedida por un boom crediticio ocurrido ante expectativas de crecimiento económico y de ingreso que no se cumplieron en la magnitud suficiente para asegurar el reembolso de la deuda. Sin embargo, las actuales crisis bancarias presentan características distintas de las crisis del pasado. Desde la Segunda Guerra Mundial y hasta la década de los ochenta, los organismos financieros internacionales, en particular el Fondo Monetario Internacional (FMI), enfrentaron fundamentalmente crisis de pagos externos, pero a partir de la crisis bancaria de México, y de manera más clara después de la crisis asiática, han presentado rasgos totalmente nuevos, pues han estallado en mercados de capitales abiertos como resultado de varios factores disfuncionales y, por lo general, no son de naturaleza exclusivamente macroeconómica, ya que asumen con gran rapidez proporciones sistémicas, de ahí que la única 
forma de contenerlas es mediante la movilización inmediata de grandes volúmenes de financiamiento (López, 2008, p. 121).

Así, la crisis financiera-inmobiliaria es resultado de la expansión de créditos otorgados a familias con escasa solvencia económica (créditos subprime o de baja calificación crediticia) en el marco de procesos de desregulación del sistema financiero y alteración especulativa de los mercados inmobiliarios, traducidos en un incremento especulativo del precio de la propiedad inmobiliaria en numerosas naciones del mundo.

El aumento inusitado de los productos financieros, resultado de la innovación financiera, contribuyó a inflar la burbuja inmobiliaria, por la fuerte especulación desatada para garantizar las ganancias a través de los títulos que financiaron la inversión en ese sector. "En pocas palabras, la valorización del capital vía este tipo de instrumentos, al llegar a cierto nivel, ocasionó la baja en su valor y posteriormente, la contracción del crédito. Así pues, la causa de la actual fragilidad financiera se encuentra en la crisis de las finanzas estructuradas" (Girón y Chapoy, 2009, p. 50).

¿Cuál es el efecto de estos procesos en las ciudades metropolitanas? Carlos De Mattos sostiene que la fase actual de desarrollo metropolitano se caracteriza por “[...] la aplicación de las políticas de desregulación, el abandono de la concepción de la planificación urbana racionalista y su reemplazo por un enfoque en el que priman los criterios de neutralidad y subsidiariedad del Estado en la gestión pública, lo que ha contribuido a consolidar un escenario más favorable para las decisiones privadas en la vida urbana; en segundo lugar, el desencadenamiento, desde mediados de la década de los años setenta, de una incontenible financierización de la economía mundial, la que se produjo al amparo de las políticas de desregulación, privatización y liberalización [...] que ha redundado en un significativo aumento de la oferta de capital inmobiliario; y tercero, la generalización de las estrategias de competitividad urbana y city marketing, impulsadas en un número creciente de ciudades con el deliberado propósito de atraer inversión externa, que han ocasionado un aumento significativo de la importancia de la inversión inmobiliaria privada" (De Mattos, 2006, pp. 55-56).

En México, siguiendo esa caracterización, desde hace veinte años los programas de vivienda han fortalecido el protagonismo de los agentes privados en la construcción en ciudades, mediante una nueva regulación que favorece la mercantilización y la expansión del crédito hipotecario. Esa política inició con la reestructuración de los organismos públicos y sus esquemas financieros, destacando la creación de la Comisión Nacional de Vivienda (CONAVI) y de la Sociedad Hipotecaria Federal (SHF) - catalogada como banca de desarrollo-, principales herramientas para facilitar el acceso al sistema financiero y canalizar recursos adicionales, provenientes del sector privado, al mercado hipotecario a través de las Sociedades Financieras de Objeto Limitado (Sofoles) ${ }^{4}$ y la banca, en el marco de un "proceso de reingeniería" cuyo objetivo es ampliar la disponibilidad financiera y la cobertura de atención.

4 Se trata de intermediarios financieros privados dedicados a financiar la construcción o la adquisición de vivienda. En la actualidad se han convertido en clientes casi exclusivos de los organismos públicos de vivienda. 
Otro rasgo es la incursión en el mercado de capitales y la emisión de valores respaldados por hipotecas, promoviendo la bursatilización de las carteras hipotecarias, en las que descansa actualmente el gran dinamismo del mercado hipotecario 5 .

Un análisis de la distribución territorial del financiamiento hipotecario en el periodo 1994-2005 permite observar varias tendencias (Cuadro 1). Primero, la mayor participación de los agentes inmobiliarios mediante la expansión del crédito hipotecario, ya que en la ZMVM la inversión por beneficiario (columna denominada promedio) prácticamente se duplicó; empero, el incremento más acentuado se encuentra en los municipios periféricos, del segundo (crecimiento de $250 \%$ ), tercero (crecimiento de $400 \%$ ) y cuarto contornos (crecimiento de $900 \%$ ), hacia donde se dirige el desarrollo de grandes complejos habitacionales, de tal suerte que la movilidad residencial tiene como sede principal a los municipios del Estado de México. Destacan en este proceso el municipio de Huixquilucan, en donde se han erigido urbanizaciones cerradas para población de altos ingresos, así como las zonas creadas en Naucalpan y Tlalnepantla como polos de concentración industrial desde los años 1940-1950, que actualmente experimentan un proceso de desindustrialización a la par que se fortalece el sector servicios. En el segundo y tercer contornos sobresalen Chicoloapan, Chimalhuacán, Chalco, Tecámac, Zumpango y Huehuetoca, municipios que, como se verá, han tenido un gran impacto inmobiliario.

A diferencia de los municipios periféricos, en la ciudad central el incremento se asocia principalmente a dos aspectos. Primero, en el año 2001 durante el gobierno de Andrés Manuel López Obrador, en el Distrito Federal entró en vigor el Bando 2 que establece medidas para redensificar las cuatro delegaciones centrales, en donde la actividad inmobiliaria encuentra escasez de suelo urbanizable y se orienta más bien a la construcción vertical de condominios. Segundo, en zonas terciarizadas prevalecen altos precios de la vivienda, puesto que los sitios de mayor plusvalía en la Ciudad de México están ubicados en las zonas centro-sur y poniente, especialmente en las delegaciones centrales (Miguel Hidalgo, Cuauhtémoc y Benito Juárez) y en barrios donde los precios de departamentos nuevos fluctúan entre mil y mil 400 dólares por metro cuadrado, según un estudio de la empresa Metros Cúbicos (Isunza, 2010, p. 297).

Si bien el impulso a la construcción de enormes unidades habitacionales es una tendencia global, pues afecta a numerosas metrópolis en el mundo, los espacios locales viven las consecuencias más graves. Además de los esquemas financieros descritos, las empresas inmobiliarias cuentan con varias ventajas en los municipios periféricos: disponibilidad y bajo precio del suelo; escasa regulación que permite a las empresas construir viviendas sin dotar de condiciones mínimas de urbanización; y arreglos políticos entre los agentes locales de distintos niveles de gobierno y las empresas constructoras.

5 A noviembre de 2007 el saldo de todas las bursatilizaciones de cartera de crédito a la vivienda colocadas en el país y en el exterior ascendió a 3 mil 110.4 millones de dólares ( 40 mil millones de pesos mexicanos considerando el tipo de cambio oficial de $\$ 12.86$ pesos por dólar al 2 de febrero de 2010). De ese total, $80 \%$ correspondió a colocaciones de créditos a la vivienda de Sofoles hipotecarias; el resto fue de bancos (BBVA Bancomer, 2008). 
CUADRO 1 | ZMVM. Créditos e inversión ejercida por contorno metropolitano y por periodo

\begin{tabular}{|c|c|c|c|c|c|c|}
\hline \multirow[b]{2}{*}{$\begin{array}{l}\text { ESCALA } \\
\text { TERRITORIAL }\end{array}$} & \multicolumn{3}{|c|}{ 1994-1999 } & \multicolumn{3}{|c|}{$2000-2005$} \\
\hline & $\begin{array}{c}\mathrm{N}^{\circ} \text { DE } \\
\text { BENEFICIARIOS }\end{array}$ & $\begin{array}{l}\text { INVERSIÓN } \\
\text { EJERCIDA (1) }\end{array}$ & $\begin{array}{c}\text { Promedio } \\
\text { (2) }\end{array}$ & $\begin{array}{c}\mathrm{N}^{\circ} \text { DE } \\
\text { BENEFICIARIOS }\end{array}$ & $\begin{array}{l}\text { INVERSIÓN } \\
\text { EJERCIDA (1) }\end{array}$ & $\begin{array}{l}\text { Promedio } \\
\text { (2) }\end{array}$ \\
\hline ZMVM & 230.991 & 22.344 .652 & 97 & 391.662 & 80.111 .708 & 205 \\
\hline Distrito Federal & 105.947 & 13.543 .119 & 128 & 234.327 & 34.343 .517 & 147 \\
\hline Ciudad central & 30.716 & 3.214 .481 & 105 & 51.252 & 12.114 .898 & 236 \\
\hline Primer Contorno & 69.858 & 8.993 .438 & 129 & 153.168 & 20.607 .752 & 135 \\
\hline Segundo Contorno & 74.536 & 7.269 .359 & 98 & 91.352 & 22.808 .540 & 250 \\
\hline Tercer Contorno & 40.590 & 2.579 .107 & 64 & 73.690 & 18.891 .566 & 256 \\
\hline Cuarto Contorno & 15.291 & 288.268 & 19 & 23.419 & 4.086 .955 & 175 \\
\hline $\begin{array}{l}\text { Municipios } \\
\text { metropolitanos (3) }\end{array}$ & 125.044 & 8.801 .534 & 70 & 157.335 & 45.768 .191 & 291 \\
\hline
\end{tabular}

Notas:

(1) Se utilizó como deflactor el Salario Mínimo Mensual vigente en el año respectivo.

(2) Inversión ejercida $/ \mathrm{N}^{\circ}$ de beneficiarios.

(3) Municipios de la ZMVM fuera del Distrito Federal.

Fuente Elaboración propia con base en CONAVI, Estadísticas de Vivienda, 1995-2005.

En un escenario signado por la escasa capacidad para generar recursos propios, los municipios compiten entre sí para atraer este tipo de inversiones. Sin embargo, la competencia no se basa en el desarrollo de potencialidades locales, sino en el precio del suelo. Un aspecto dramático es la reacción de los pequeños agricultores arruinados que ven en la venta de sus tierras un costo de oportunidad, en relación al precario ingreso y baja productividad de las actividades rurales. Así, la disponibilidad de suelo urbanizable es mayor en municipios alejados de las zonas que ejercen la centralidad urbana. Debido a que la autorización para la construcción de nuevas viviendas es competencia del gobierno estatal, los municipios con menor grado de urbanización y que, en general, disponen de zonas agrícolas más amplias, señalan en el Plan de Desarrollo Urbano Municipal mayor superficie urbanizable que los municipios consolidados o con altos niveles de urbanización.

Una consecuencia de la aplicación de esta política desreguladora en la periferia de la Ciudad de México, es la configuración de un patrón de asentamientos huma- 
nos fragmentado y disperso que no garantiza las condiciones mínimas de urbanización y, por tanto, no responde a la creciente demanda de los nuevos habitantes que originalmente salen de las áreas centrales e intermedias de la ciudad.

\section{Los desarrollos inmobiliarios en la periferia}

Un proceso actual en las grandes aglomeraciones urbanas es el paso de un patrón de asentamientos de alta densidad poblacional a uno de urbanización dispersa y más fragmentada. Este tipo de estructura territorial, denominada por algunos investigadores (Aguilar, 2002; Monclús, 1998) nuevas periferias, deriva de la dinámica de la suburbanización o periurbanización que experimentan la mayoría de las ciudades de carácter metropolitano, correspondiéndole a las migraciones, particularmente las intraurbanas, jugar un rol decisivo en su conformación. La expansión urbana de la Ciudad de México no ha sido un proceso continuo que se dirija indistintamente a todas direcciones. Todo lo contrario, ésta se ha desarrollado mediante extensiones periódicas del área urbana, seguidas de etapas de contención en las cuales las zonas incorporadas experimentan procesos de densificación, y los límites externos o la periferia no se modifican sustancialmente. Además, estos procesos parecen alternarse entre el Distrito Federal y los municipios del Estado de México que se van incorporando a la dinámica metropolitana (Connolly, 1988, 2005; Duhau, 1998).

Según la información censal, el Distrito Federal registra una tasa de emigración de 2.1, que representa casi 4.5 millones de personas; en tanto la de inmigración es 0.9 correspondiente a 1.8 millones; o sea, expulsa 2.6 millones de personas, mientras el Estado de México recibe 4.4 millones. Así, el 23\% de la población residente en el Estado de México en el año 2005 nació en el Distrito Federal, y de la población residente en éste, solo 3,3\% provino del Estado de México (INEGI, 2005). La Muestra Censal (INEGI, 2000) indica que el Distrito Federal perdió cerca de 287 mil personas, quienes mudaron su residencia al Estado de México, principal entidad de destino, provocando en los municipios metropolitanos un crecimiento demográfico promedio de $1,4 \%$.

Paulatinamente, en la ciudad central y los municipios del primer contorno aparecen saldos negativos de movilidad residencial y tasas de crecimiento inferiores a la unidad. Las pérdidas más abruptas ocurrieron en la delegación Gustavo A. Madero, donde más de 79 mil personas se trasladaron principalmente a Ecatepec, Nezahualcóyotl, Tlalnepantla, Ixtapaluca e Iztapalapa. El segundo lugar lo ocupa la delegación Venustiano Carranza, que perdió más de 45 mil personas. En correspondencia, las jurisdicciones del segundo contorno tuvieron un incremento de población de casi 289 mil personas. Estas tendencias confirman un patrón de movilidad residencial que va de las áreas intermedias a las del tercer y cuarto anillo de conurbación, superando el esquema migratorio clásico centro-periferia (Isunza, 2010).

Asimismo, la dinámica de la ciudad proviene cada vez menos de su crecimiento natural y en gran medida de la migración urbana-urbana y metropolitana-urbana; es decir, se define principalmente por los flujos internos o intrametropolitanos. 
En este contexto ¿cómo entender la periferia? Más allá de considerarse como una condición de la expansión urbana, las zonas de las ciudades a las cuales se ha denominado genéricamente "periferia" constituyen espacios complejos en los que tienen lugar diversas formas de producción de la ciudad y procesos de diferenciación social y en donde se encuentran imbricados distintos agentes sociales, áreas y estilos de vida rurales así como distintas formas de propiedad. El tema del suelo urbano alude directamente a las formas de expansión y ocupación del suelo urbanizado y urbanizable. Su evolución y ritmo depende tanto de las políticas locales aplicadas en el espacio urbano que impulsan, promueven o contienen la urbanización, como de las formas de ocupación del suelo, referidas a la existencia de agentes sociales y económicos que producen la ciudad, ya sea a partir del desarrollo de actividades económicas industriales, comerciales o de servicio, o en calidad de productores de soportes materiales como infraestructura, equipamientos o vivienda. Ello conduce a la interacción de propietarios del suelo, promotores inmobiliarios, industria de la construcción y sectores demandantes de vivienda; todos ellos con intereses propios y frecuentemente contradictorios. Por lo tanto, la política urbana interioriza acciones y decisiones públicas que inciden en la transformación de la estructura urbana, contando principalmente con los instrumentos de planeación que establecen las normas, procedimientos, objetivos, planes y programas para inducir la configuración de ciertas características de la ciudad (Duahu y Cruz, 2006). Por el impacto de las acciones de producción de vivienda en la periferia urbana de la Ciudad de México durante la última década, este trabajo enfoca su atención en los promotores inmobiliarios.

Un rasgo permanente en la urbanización de la ZMVM ha sido el acceso a la vivienda a partir de la incorporación irregular del suelo periférico al uso habitacional popular, mediante la autoconstrucción. Pero esta oferta ha cambiado, dejando de ser el elemento central. La experiencia de los años ochenta del siglo pasado muestra que paralelamente a la participación de áreas de propiedad ejidal ${ }^{6}$, ha crecido significativamente la oferta de suelo de propiedad privada, bajo la modalidad de pequeña propiedad agraria o de predios propiedad de antiguos habitantes, a precios más bajos que en el mercado formal, sea por factores de localización, escasa o nula dotación de infraestructura, o por la irregularidad jurídica (Duhau y Cruz, 2006, p. 424).

La política de expansión del crédito hipotecario favorece el dinamismo del capital inmobiliario; en su papel como determinante de la movilidad residencial, esta modalidad de crecimiento urbano ha provocado un gran impacto: en el periodo 1999-2008 se autorizó el desarrollo de 293 conjuntos habitacionales, con cerca de 488 mil viviendas para poco más de 2 millones 240 mil personas, en 27 municipios de la ZMVM, con un consecuente incremento de la población que cambia su residencia (Cuadro 2).

6 Producto de la reforma agraria, en México el ejido es una forma de tenencia de la tierra sui generis, que se refiere al conjunto de bienes territoriales recibidos por un núcleo de población a través de un proceso legal denominado dotación. La incorporación al suelo urbano de las tierras ejidales fue posible a partir de la aprobación de la Ley Agraria de 1992 y de las actualizaciones realizadas a la Ley General de Asentamientos Humanos. 
CUADro 2 | Conjuntos habitacionales autorizados en los municipios del Estado de México pertenecientes a la ZMVM (1999-2008)

\begin{tabular}{c|c|c|c}
\hline AÑo & NúMERo & VIVIENDAS & POBLACIÓN BENEFICIADA \\
\hline 1999 & 2 & 2.877 & 12.947 \\
2000 & 15 & 34.635 & 155.858 \\
2001 & 11 & 20.032 & 90.145 \\
2002 & 17 & 40.283 & 181.275 \\
2003 & 32 & 56.043 & 252.340 \\
2004 & 44 & 90.573 & 407.743 \\
2005 & 37 & 62.312 & 280.408 \\
2006 & 42 & 53.896 & 242.538 \\
2007 & 24 & 17.898 & 84.862 \\
2008 & 262 & 49.398 & 262.799 \\
\hline TotAL & 48 & 428.797 & 1.974 .740 \\
\hline
\end{tabular}

fuente Gobierno del Estado de México, Secretaría de Desarrollo Urbano. HYPeRLinK “http://www. EDOMEX.GOB.MX/SEDUR/ESTADISTICAS/CONJUNTOS-URBANOS”HTTP://WWW.EDOMEX.GOB.MX/SEDUR/ESTADISTICAS/CONJUNTOS-URBANOS

La mayor parte de estos desarrollos se ubican en el tercer y cuarto contornos metropolitano (zona oriente), destacando seis municipios: Tecámac, Zumpango, Huehuetoca, Chicoloapan, Chalco y Ecatepec que concentran la mitad de los conjuntos autorizados, $66 \%$ de las viviendas construidas y $64 \%$ de la población beneficiada, por lo que se consideran representativos para los efectos de la presente investigación (Cuadro 3).

CUADRO 3 | ZMVM. Municipios metropolitanos más importantes receptores de conjuntos habitacionales 1999-2008

\begin{tabular}{l|c|c|c}
\hline \multicolumn{1}{c|}{ Municipio } & $\mathbf{N}^{\circ}$ DE CONJUNTOS & Viviendas & Población BENEFICIADA \\
\hline Tecámac & 36 & 102.184 & 459.994 \\
Zumpango & 24 & 48.223 & 221.323 \\
Huehuetoca & 20 & 41.943 & 188.743 \\
Chicoloapan & 23 & 38.863 & 174.884 \\
Chalco & 13 & 28.409 & 127.840 \\
Ecatepec & 14 & 22.066 & 99.297 \\
Suma 6 Municipios & 130 & 281.688 & 1.272 .081 \\
\hline TotaL & 262 & 428.797 & 1.974 .740 \\
\hline
\end{tabular}

fuente Elaboración propia con datos de Secretaría de Desarrollo Urbano, Gobierno del Estado de MÉXICO. 
La disponibilidad de suelo se constata en cinco de los municipios seleccionados: Tecámac cuenta con 6 mil 103 hectáreas de superficie urbanizable (39,7\% de la superficie municipal); Tultitlán 4 mil 933 hectáreas (15,8\%); Zumpango 3 mil 158 hectáreas (9,5\%); Huehuetoca 3 mil 193 hectáreas (19\%); Chicoloapan mil 60 hectáreas (15\%) y Chalco mil 854 hectáreas (8\%). En municipios con alto grado de consolidación urbana, como Ecatepec, la construcción de unidades habitacionales ocasiona un alto impacto en la densidad de población. Por ello, el Plan Municipal de Desarrollo Urbano de Ecatepec 2006-2012 reporta el agotamiento del suelo urbanizable y establece como prioridad la redensificación y la ocupación de vacíos urbanos. Así, los municipios señalados se han convertido en importantes lugares de destino de una población que previamente residía en las áreas centrales y primeros contornos metropolitanos de la Ciudad de México. Es claro entonces que los desarrolladores de vivienda a gran escala aseguran la disponibilidad de suelo urbanizable en espacios periurbanos cada vez más alejados de la ciudad central, debido al alto precio del suelo en las zonas terciarizadas y a la creciente escasez de suelo urbanizable, lo que configura un mercado estratificado, que reserva las zonas centro-sur y poniente de la ciudad a la población de altos ingresos (Isunza, 2010, p. 299).

Sin embargo, debido a la forma en que se diseñan estas grandes unidades habitacionales, con la idea de exclusividad y altos niveles de seguridad que la publicidad promueve, se han convertido en núcleos aislados, sin integración funcional con las modalidades de poblamiento preexistentes, sean pueblos conurbados, zonas de urbanización popular, o bien, zonas donde aún prevalecen actividades y estilos de vida rurales. Este es un rasgo de un nuevo estilo de crecimiento urbano que no contribuye a vencer el rezago habitacional.

Por otro lado, se puede afirmar que existe un desfase entre los ritmos de crecimiento de la vivienda y el grado de urbanización, especialmente porque los nuevos residentes que arriban a los municipios periféricos enfrentan -aunque con distinta magnitud- problemas socioambientales ligados al déficit en la dotación de servicios y a la falta de integración social de la población residente en las nuevas unidades habitacionales con los asentamientos humanos colindantes. Por ejemplo, en el Plan de Desarrollo Urbano de Chicoloapan (2001-2012, p. 45) se afirma: "Como en todos los municipios en los que la presión por ocupación del suelo rebasa la capacidad de control de los propios ayuntamientos, la administración municipal tiene problemas para dotar de servicios a las zonas de nueva incorporación urbana, más aún cuando se trata de asentamientos humanos en zonas no abiertas al desarrollo habitacional".

En resumen, las tendencias de los últimos treinta años muestran una ruptura en el ciclo urbano, toda vez que la actividad inmobiliaria promueve la conformación de núcleos relativamente aislados de población, con escasa vinculación funcional con el entorno municipal y regional. Asimismo, la incorporación de extensas superficies en la periferia no sigue los patrones de las zonas previamente urbanizadas, porque avanza de manera discontinua, integrando áreas periféricas con bajos niveles de urbanización, baja densidad y donde en muchos casos, aún prevalecen actividades y estilos de vida rurales. 
En consecuencia, los retos de la gestión municipal en el marco de la dinámica metropolitana de la Ciudad de México se vinculan estrechamente a los procesos de urbanización, especialmente a la forma en la que distintos agentes intervienen en la producción del espacio habitable y a la intensa movilidad de la población por motivos residenciales, no obstante.

Otra característica de este proceso es la concentración del desarrollo de conjuntos habitacionales en sólo trece consorcios dedicados a la industria de la construcción con gran actividad, tanto en el Estado de México como en todo el país, a los que se les ha autorizado más del 60\% de los conjuntos habitacionales (gobierno del Estado de México, Secretaría de Desarrollo Urbano). Esto se relaciona con la configuración política de los gobiernos que confluyen en este espacio metropolitano, así como por las aspiraciones de sus titulares a contender por la presidencia del país en el año 2012. El Distrito Federal es gobernado desde 1997 por el Partido de la Revolución Democrática (centro-izquierda); el gobierno del Estado de México procede del Partido Revolucionario Institucional (PRI) que durante más de 70 años y hasta el año 2000 (cuando perdió con el Partido de Acción Nacional, de centro-derecha), detentó la Presidencia en México. En virtud del pragmatismo político que subyace en las actuaciones de los actores políticos, la promoción inmobiliaria es objeto de marketing electoral. Un reportaje periodístico pone en evidencia que las empresas autorizadas para desarrollar los megaproyectos inmobiliarios en el Estado de México tienen fuertes nexos con el actual gobernador Enrique Peña Nieto, a través de la asociación Ayúdame que yo también soy Mexicano, que afilia a prominentes empresarios locales, familiares y amigos del gobernador (Reporte Índigo, 2010).

\section{El marco regulatorio para la gestión municipal en el Estado de México}

El añejo, pero vigente centralismo mexicano dio un pequeño paso atrás con las reformas de 1983 y 1999 al artículo 115 de la Constitución Política de los Estados Unidos Mexicanos, cuya fracción III dice: "Los municipios, con el concurso de los Estados cuando así fuere necesario y lo determinen las leyes, tendrán a su cargo los siguientes servicios públicos: a) Agua potable y alcantarillado; b) Alumbrado público; c) Limpieza; d) Mercados y centrales de abasto; e) Panteones; f) Rastro; g) Calles, parques y jardines; h) Seguridad pública y tránsito; i) Los demás que las legislaturas locales determinen según las condiciones territoriales y socioeconómicas de los municipios, así como su capacidad administrativa y financiera” (Congreso, 1917).

Para realizar esas funciones, la fracción IV establece que: "Los municipios administrarán libremente su hacienda, la cual se formará de los rendimientos de los bienes que les pertenezcan, así como de las contribuciones y otros ingresos que las legislaturas establezcan a su favor, y en todo caso: a) percibirán las contribuciones, incluyendo tasas adicionales, que establezcan los Estados sobre la propiedad inmobiliaria, de su fraccionamiento, división, consolidación, traslación y mejora así como las que tengan por base el cambio de valor de los inmuebles. Los municipios podrán celebrar convenios con el Estado para que éste se haga cargo de algunas de 
las funciones relacionadas con la administración de esas contribuciones. b) Las participaciones federales, que serán cubiertas por la Federación a los municipios con arreglo a las bases, montos y plazos que anualmente se determinen por las legislaturas de los Estados. c) Los ingresos derivados de la prestación de servicios públicos a su cargo" (Congreso, 1917).

En materia de regulación territorial, la fracción $V$ señala que: "Los municipios, en los términos de las leyes federales y estatales relativas, estarán facultados para formular, aprobar y administrar la zonificación y planes de desarrollo urbano municipal; participar en la creación y administración de sus reservas territoriales; controlar y vigilar la utilización del suelo en sus jurisdicciones territoriales; intervenir en la regularización de la tenencia de la tierra urbana; otorgar licencias y permisos para construcciones, y participar en la creación y administración de zonas de reservas ecológicas". (Congreso, 1917).

Sin embargo, el decreto correspondiente estableció en su artículo segundo transitorio que "El Congreso de la Unión y las legislaturas de los Estados, en el plazo de un año computado a partir de la vigencia de este Decreto, procederán a reformar y adicionar las leyes federales, así como las Constituciones y leyes locales..." (DOF, 1983). Esta disposición permitió que, en algunos casos, la transferencia de facultades no llegara al municipio, sino se estancara en los gobiernos estatales.

Años después, un balance general de la reforma en los Estados indica que a pesar del evidente avance en las competencias de los municipios, aún permanecen pendientes algunos aspectos como: otorgar expresamente autonomía al municipio; el reconocimiento de usos y costumbres en los municipios indígenas; permitir la reelección inmediata de los presidentes municipales; reconocer al municipio como autoridad fiscal; obligar a la federación a transferir con transparencia y rapidez los recursos fiscales, sin intermediación de las legislaturas estatales, que se han convertido en una nueva aduana; reconocer la heterogeneidad municipal; establecer las bases para incorporar la participación ciudadana en decisiones municipales, así como definir la responsabilidad del municipio en la promoción del desarrollo económico (Guillén y Ziccardi, 2004, pp. 32-33). Además, en algunos Estados, al menos parcialmente, las funciones asignadas a los municipios en el artículo 115 constitucional son ejercidas por el ejecutivo estatal.

Así, en la reforma del año 2001 a la Constitución Política del Estado Libre y Soberano de México en materia municipal destacan los artículos 61, 77, 122, 125 y 126 (Congreso, 2001) en los que, como en otras entidades (Guillén y Ziccardi, 2004), el avance de mayor trascendencia fue reconocer la capacidad de asociación entre municipios para la prestación de servicios y fortalecer la hacienda municipal en el uso de sus recursos. Pero, en detrimento de las atribuciones que el artículo 115 de la constitucional nacional pretendió trasladar a los municipios, el artículo 31 de la Ley Orgánica de la Administración Pública del Estado de México otorga amplias facultades a la Secretaría de Desarrollo Urbano y Vivienda en materia de regulación de la tenencia de la tierra (fracciones XI y XII), para autorizar subdivisiones, fusiones, relotificación de predios y conjuntos urbanos (fracción XIII), establecer programas de reservas territoriales, destinos y usos del suelo (fracciones XIV y XV), 
impulsar el financiamiento de los asentamientos humanos y el desarrollo urbano (fracción XVI) (Congreso, 2008) 7 .

Un sentido similar de restricción se encuentra en la Ley Orgánica Municipal del Estado de México (artículos 11, 12, 31 fracción XXIV y 33 fracción VII) (Congreso, 2009a), en la Ley de Planeación del Estado de México y Municipios (artículo 19 fracción III) (Congreso, 2007). Por su parte, la Ley de Vivienda (artículos 12 fracciones IV y V) va aun más allá, al facultar al gobernador a suscribir convenios con el sector privado y a expedir los reglamentos que esa ley requiera (Congreso, 2009b).

En el Estado de México el aparato de gobierno reservó para sí importantes funciones, pero no las ha ejercido a plenitud. Muestra de ello es la deficiencia en la dotación de servicios como el drenaje en las zonas de desecación del Lago de Tex$\operatorname{coco}^{8}$ al oriente de la ZMVM, a pesar de que la fracción VII del artículo 31 de la Ley Orgánica de la Administración Pública del Estado de México responsabiliza a la Secretaría de Desarrollo Urbano y Vivienda de "Vigilar el cumplimiento de las normas técnicas en materia de desarrollo urbano, vivienda y construcciones" (Congreso, 2008).

En síntesis, los municipios del Estado de México disponen en los hechos de escasas facultades para intervenir en el desarrollo urbano, razón por la cual deben atender necesidades que rebasan con mucho sus exiguas capacidades, en un esfuerzo condenado de antemano al fracaso. Empero, los gobiernos estatales o subnacionales, a pesar de disponer de una gama mucho más amplia de atribuciones para regular la producción de suelo urbano, comúnmente tampoco tienen éxito en su gestión, quizás por falta de visión metropolitana y nacional, por simple ineficiencia de las agencias, por corrupción, o por una mezcla de estos factores y otros más.

Ante esta evidencia y considerando que el estilo de urbanización basado en las acciones del capital inmobiliario no es una peculiaridad de la ZMVM, sino que forma parte de una tendencia mundial, es razonable preguntar ¿En qué nivel de gobierno deben establecerse las competencias en materia de desarrollo urbano? pues una premisa de la acción pública debe necesariamente ser el cumplimiento de las funciones asignadas.

Desde la perspectiva de las corrientes de la gestión pública, que favorecen la sustitución del modelo organizativo piramidal, centralizado, burocrático y autoritario vigente en México, por otro caracterizado por una mayor fluidez, flexibilidad y trabajo en equipo, la descentralización a nivel municipal de las decisiones en torno a la asignación de recursos y la prestación de servicios a la población es una recomendación de carácter estratégico (OCDE, 1997). Un importante argumento a favor de esta postura reside en el conocimiento que los gobiernos locales poseen de las necesidades inmediatas de la población.

7 El procedimiento detallado, incluyendo formatos, de 22 trámites para conjuntos urbanos puede consultarse en: http://www.edomex.gob.mx/sedur/conjuntos-urbanos/tramites.

8 Zona donde se produjeron entre 1934 y 1939, dos grandes extensiones de terreno plano, con gran compresibilidad en su subsuelo y salinidad; sin tener resuelto el problema del desalojo de las aguas pluviales y servidas, que se manifestaba en serias inundaciones; una al poniente del Lago de 6 mil 335 hectáreas y otra al sur de 4 mil 650 hectáreas, en esta última creció Ciudad Nezahualcóyotl (Covarrubias, 2000:5). 
Empero, es necesario admitir que actualmente en México la mayor parte de los municipios carecen de infraestructura, personal capacitado y recursos presupuestales autogenerados -como se examinará posteriormente- para ejercer las competencias que según la Constitución les corresponden, y probablemente carecen también de una visión metropolitana para dimensionar su condición actual, potencial y límites de crecimiento, de manera que al ignorar la magnitud de los retos a enfrentar con el arribo de miles de nuevos residentes, suelen ser abrumados por las ofertas de las empresas inmobiliarias.

A esta situación se agrega el diferente lugar que un problema ocupa en las agendas de los tres niveles de gobierno de México, así como la dispersión y falta de coordinación entre programas del gobierno federal. Un ejemplo de ello es el manejo de los residuos sólidos, pues el Programa Nacional para la Prevención y Gestión Integral de los Residuos 2009-2012 encargado de diseñar los lineamientos de política a nivel nacional fue publicado en el Diario Oficial de la Federación, a casi tres años de iniciado el sexenio del actual gobierno federal (DOF, 2009), mientras en los municipios existe coincidencia en ubicarlo como un problema de primer orden. En otro ejemplo, ante la notable disparidad en los niveles de desarrollo de los municipios y los problemas específicos que cada uno de ellos enfrenta, desde la óptica de las políticas focalizadas, se han creado a nivel federal un gran número de Programas que bajo cinco modalidades (Ramo 28, Ramo 33, Excedentes de Ingresos Federales, Convenios de Reasignación de Recursos y Gastos de Programas Federales) (Secretaría de Gobernación, 2007, p. 21) transfieren recursos a los gobiernos locales. La gran cantidad de Programas ha dado lugar a un catálogo, del cual cada autoridad municipal selecciona, aplicando sus propios criterios, aquellos que considera más apropiados.

\section{Finanzas y gestión en los municipios}

El escenario de las finanzas públicas municipales se torna poco alentador en un contexto recesivo que agudiza los enormes retos derivados de la dependencia de los recursos federales ante su poca capacidad recaudatoria y la mala administración de los mismos. Al parecer, con el auge inmobiliario, la mayoría de los municipios únicamente le apuestan al cobro del impuesto predial como opción para ampliar sus ingresos, omitiendo otras fuentes como los impuestos al comercio, al turismo y la participación de asociaciones vecinales o empresas en algunas actividades.

Tras reflexionar sobre la magnitud e impacto de las nuevas viviendas, así como sobre las atribuciones reales de los municipios en el Estado de México en materia de desarrollo urbano, con el propósito de completar el panorama de su capacidad de gestión, conviene atisbar en los asuntos relacionados con el ingreso, su correspondiente presupuesto y el uso que de ellos hacen los gobiernos locales, toda vez que las competencias de gobierno son casi letra muerta si se carece de recursos económicos para ejecutarlas. Así, para analizar el comportamiento financiero de los municipios resulta útil un somero acercamiento a cuatro indicadores básicos según las metodologías propuestas por Cabrero (1996, p. 66; 2005, pp. 134-135) y por el Instituto 
Nacional para el Federalismo y el Desarrollo Municipal (INAFED). Ellos son: el ingreso per cápita por derechos, la autonomía financiera, la dependencia de las participaciones federales y la autonomía para asumir el gasto operativo.

Desde el punto de vista de las posibilidades de obtención de recursos, cuyo panorama general se indicó en la fracción IV del artículo 115 de la Constitución Nacional, el indicador del ingreso per cápita por derechos ${ }^{9}$ (el total de ingresos por derechos obtenidos por un municipio en un año, dividido entre el total de población residente en ese municipio para ese año), examina el nivel de autofinanciamiento de los servicios públicos, como el suministro de agua potable, el registro civil, el registro público de la propiedad y el comercio, la expedición de licencias, las cuotas por servicios médicos, entre otros, que el gobierno municipal otorga a sus ciudadanos. El Cuadro 4 presenta los cálculos efectuados para el periodo 2002-2007 en el grupo de seis municipios seleccionados por la magnitud de los desarrollos habitacionales que constituyen el caso representativo de este estudio. Destaca Huehuetoca, cuyo sistema de cobro por los servicios otorgados parece ser mucho más eficiente que en los otros cinco municipios considerados. En el extremo opuesto se encuentra Ecatepec, en donde quizás un enorme padrón de ciudadanos dificulte una eficiente política de cobro. Chicoloapan presenta una tendencia de declive en la obtención de ingresos por esta vía, probablemente revelando incapacidad para incorporar en su sistema de cobro a los nuevos vecinos, que contrasta con un ascenso sostenido en Zumpango.

CUADRO 4 | Ingreso per cápita por Derechos en municipios seleccionados del Estado de México

\begin{tabular}{l|c|c|c|c|c|c}
\hline Año & $\mathbf{2 0 0 2}$ & $\mathbf{2 0 0 3}$ & $\mathbf{2 0 0 4}$ & $\mathbf{2 0 0 5}$ & $\mathbf{2 0 0 6}$ & $\mathbf{2 0 0 7}$ \\
\hline Tecámac & 92,3 & 91,7 & 56,7 & 68,4 & 107,1 & 176,4 \\
Zumpango & 69,2 & 69,0 & 82,2 & 156,2 & 135,6 & 122,4 \\
Huehuetoca & 144,5 & $\mathrm{nd}$ & 355,7 & 308,3 & 515,6 & 404,7 \\
Chicoloapan & 82,0 & 57,6 & 87,2 & 48,1 & 33,1 & 31,6 \\
Chalco & 36,6 & 47,2 & 78,6 & 51,8 & 53,7 & 63,0 \\
Ecatepec & 47,8 & 143,0 & 164,4 & 24,3 & 30,2 & 29,1 \\
\hline
\end{tabular}

FUENTE ELABORACIÓN PROPIA CON BASE EN INEGI, CONSUlTA ELECTRÓNICA HYPERLINK "HTTP:// WWW.INEGI.ORG.M X/PROD_SERV/CONTENIDOS/ESPANOL/BIBLIOTECA/DEFAULT.ASP?ACCION=\%20 4\&UPC=702825001731"HTTP://WWW.INEGI.ORG.MX/PROD_SERV/CONTENIDOS/ESPANOL/BIBLIOTECA/DEFAULT. ASP ACCION $=4 \& U P C=702825001731$.

Para completar el acercamiento a la situación financiera de los seis municipios señalados, el Cuadro 5 muestra las diferencias entre ellos en tres indicadores con

Definidos por el INEGI como las "Contribuciones establecidas en la ley por el uso o aprovechamiento de los bienes de dominio público, así como por los servicios que presta el estado en sus funciones de derecho público, excepto cuando se prestan por organismos descentralizados". www.inegi.org.mx/prod_serv/contenidos/ espanol/biblioteca/ default.asp ?accion $=4 \& \mathrm{UPC}=702825001731$. 
datos de los años 2005 y 2008. El primero es la autonomía financiera ${ }^{10}$, definida por el INAFED como “... la relación entre el ingreso propio de los municipios y los ingresos totales que tuvieron en un ejercicio fiscal, lo cual da cuenta de su capacidad de explotar sus propias fuentes de ingreso, pero además indica en qué medida puede cubrir sus gastos totales sin la intervención de otros niveles de gobierno". El segundo, la dependencia de aportaciones federales, entendida como "... la relación existente entre las aportaciones federales y el total de los ingresos que percibe el municipio...", es decir, la suma de las aportaciones que la federación entrega a un municipio, dividido entre los ingresos totales, multiplicado por cien; este indicador revela el tamaño de las participaciones federales en los ingresos de un gobierno local. El tercero, la autonomía para asumir el gasto operativo, muestra la relación entre el gasto corriente y los ingresos propios [(Ingresos propios/ Gasto corriente) ${ }^{*} 100$ ], establece en qué medida a partir de sus propios recursos el municipio es capaz de cubrir su gasto de operación.

Respecto al primer indicador, ningún municipio de los aludidos es capaz de obtener al menos la mitad de su gasto mediante los ingresos propios (impuestos, derechos, aprovechamientos, aportaciones para mejoras, productos y otros) en los años examinados. En consecuencia, la autonomía financiera revela que los ingresos propios representan sólo una pequeña parte del ingreso total, con un comportamiento inestable. En lo referente a la dependencia de aportaciones federales, los datos para 2005 y 2008 revelan, incluso tras un periodo de impacto de las acciones inmobiliarias, una continuidad en la sujeción a la intervención del gobierno federal; o sea, que las participaciones federales siguen constituyendo la fuente más importante de ingresos en estos municipios. Finalmente, los indicadores de la autonomía para asumir el gasto operativo tampoco muestran un crecimiento consistente en los ingresos propios. Es decir, la evidencia señala que el acelerado crecimiento urbano no ha sido incapaz de aportar recursos crecientes a los municipios, o que los gobiernos municipales no han encontrado la forma de aumentar sus ingresos.

Los indicadores examinados en los cuadros 4 y 5 revelan la presencia de importantes debilidades en las áreas de tesorería de la administración municipal que hacen evidente la difícil tarea de la gestión pública cuando a un notable rezago en la dotación de servicios públicos, agravado por el arribo en plazos cortos de decenas de miles de nuevos residentes, se suma la escasa captación de ingresos de un gobierno local. Así, los municipios enfrentan una serie de retos: los relacionados con los pocos organismos operadores de servicios públicos autónomos y financieramente sanos. "El modelo de organismo independiente de la administración local ha sido utilizado en los municipios grandes, de ellos son pocos los que han dado el salto al uso de tecnología de vanguardia. Los casos más notables se encuentran en agua potable. Pero, a pesar de ser este servicio una fuente potencial muy importante de ingresos para el municipio, la mayoría de los organismos

Cociente entre los ingresos propios y el gasto total, multiplicado por cien. 
operadores trabajan con números rojos. Tal situación se explica entre otras razones por una mala y desactualizada política tarifaria, pero también por la tradición de cobro por cuota fija que incentiva el consumo desmedido, lo que provoca una fuerte ineficiencia operativa y financiera. Adicionalmente, el manejo político del agua potable ha contribuido a crear una cultura muy extendida del 'no pago' por dicho servicio" (Rojo, 2009, p. 2). Esta situación es más grave en el caso de la recolección de residuos sólidos y alumbrado público, ya que más que una fuente de ingresos, representan un rubro importante de gasto público y suelen catalogarse como áreas conflictivas para las administraciones locales (Rojo, 2009).

CUADRO 5 | Comportamiento financiero de los municipios seleccionados del Estado de México, 2005-2008

\begin{tabular}{|c|c|c|c|c|c|c|}
\hline & $\begin{array}{l}\text { AUTONOMÍA } \\
\text { FINANCIERA }\end{array}$ & $\begin{array}{c}\text { DEPENDENCIA } \\
\text { PARTICIPACIONES } \\
\text { FEDERALES }\end{array}$ & $\begin{array}{c}\text { AUTONOMÍA } \\
\text { PARA ASUMIR } \\
\text { GASTO } \\
\text { OPERATIVO }\end{array}$ & $\begin{array}{l}\text { AUTONOMÍA } \\
\text { FINANCIERA }\end{array}$ & $\begin{array}{c}\text { DEPENDENCIA } \\
\text { PARTICIPACIONES } \\
\text { FEDERALES }\end{array}$ & $\begin{array}{c}\text { AUTONOMÍA } \\
\text { PARA ASUMIR } \\
\text { GASTO } \\
\text { OPERATIVO }\end{array}$ \\
\hline & \multicolumn{3}{|c|}{2005} & \multicolumn{3}{|c|}{2008} \\
\hline Tecámac & 38,72 & 22,47 & 50,82 & 31,81 & 26,11 & 38,06 \\
\hline Zumpango & 22,82 & 30,34 & 30,93 & 33,19 & 31,93 & 48,4 \\
\hline Huehuetoca & 32,56 & 35,95 & 45,89 & 39,09 & 25,1 & 52,03 \\
\hline Chicoloapan & 28,2 & 41,51 & 29,05 & 9,42 & 25,22 & 22,78 \\
\hline Chalco & 11,79 & 24,84 & 18,65 & 15,79 & 27,62 & 24,65 \\
\hline Ecatepec & 13,96 & 27,46 & 21,55 & 16,05 & 36,47 & 21,12 \\
\hline
\end{tabular}

FUENTE INAFED.- INDICADORES FINANCIEROS DE LOS MUNICIPIOSHYPERLINK “HTTP://WWW.INAFED.GOB. MX/WB/INAFED09/INDICADORES_MUNICIPALES"HTTP://WWW.INAFED.GOB.MX/WB/INAFED09/INDICADORES_ MUNICIPALES.

Otro grupo de problemas derivan del bajo nivel de capacitación de los tesoreros municipales; el bajo nivel de desarrollo de los proyectos público-privados; la estructura de gasto con alto porcentaje de gasto corriente (gasto de operación, destinado al pago de servicios personales, materiales, suministros y servicios generales) suele ser el componente mayoritario del gasto municipal y la falta de estrategias adecuadas para consolidar montos importantes para obras más grandes, ya que es común el desconocimiento de los programas, tanto estatales como federales, que pueden multiplicar los montos de inversión destinados por los municipios para obras de infraestructura importantes (Rojo, 2009, pp. 2-3).

\section{Reflexiones finales}

La globalización es un fenómeno que ha transformado en pocos años la forma de organizar la producción, el comercio, la intervención de los gobiernos en la actividad económica, y en general el estilo de vida de un creciente porcentaje de la 
población en todo el planeta. Una de sus múltiples aristas es, sin duda alguna, el surgimiento de una nueva modalidad de urbanización cuyo rasgo más visible es el auge inmobiliario orientado a la construcción de numerosos conjuntos habitacionales, con miles de miles de viviendas construidas en serie, con el mismo modelo y color en la periferia de las ciudades en un número cada vez mayor de países. Bajo este influjo, el panorama en los espacios circundantes de las ciudades latinoamericanas, en donde por muchos años la urbanización irregular y la vivienda progresiva, carente de apoyo crediticio y sin servicios básicos fueron características, se modifica aceleradamente. Esta dinámica inmobiliaria no sólo ha transformado la imagen de grandes urbes y pequeñas ciudades, haciendo aparecer en plazos muy cortos suburbios casi idénticos, sino que también ha planteando a la población y a los gobiernos nuevos desafíos.

Este es el caso de la periferia de la ZMVM, en donde el desarrollo de nuevos conjuntos habitacionales fomenta la fragmentación de los núcleos urbanos, un creciente flujo de población y, por ende, demandas sociales que los gobiernos municipales no son capaces de solventar, pues disponen de un pequeño margen de acción tanto en el ámbito de las limitadas competencias que la legislación en el nivel subnacional les otorga, como en la posibilidad real de ejercerlas, pues la eficiencia del sector público requiere de crecientes recursos económicos, personal capacitado, instituciones estables, uso de tecnología apropiada, experiencia y disposición política para actuar, entre otros.

El espejismo de los grandes conjuntos habitacionales y su caudal de generación de empleos para construirlos, el efecto multiplicador esperado en la economía local, el incremento de los ingresos gubernamentales por diversos permisos e impuestos, entre los que destaca el predial, además de los beneficios de tipo político provocados por el aumento de potenciales votantes, han obnubilado a los encargados de la administración pública, al grado de colocar a las ventanillas oficiales en calidad de solícitas oficinas de tramitación al servicio de las grandes empresas constructoras, dispuestas no sólo a omitir violaciones a las leyes y reglamentos en el diseño de proyectos y en su ejecución, sino incluso a ofrecer condiciones adicionales para competir con otros gobiernos.

Así, la disputa por el privilegio de contar con un nuevo conjunto habitacional ensombrece el elevado impacto que el territorio y su población asumen en materia de daño ambiental, congestionamiento vial, segregación, déficit en servicios como drenaje, agua potable, electrificación de espacios públicos, educación, áreas de esparcimiento y deterioro de la seguridad de los ciudadanos, que no pueden ser compensados por los magros ingresos obtenidos con la nueva modalidad de urbanización. Por eso, es posible afirmar que tanto en términos de competencias, como en su capacidad financiera los municipios del Estado de México ofrecen limitadas expectativas de intervención en el desarrollo urbano de su propio territorio, condición que probablemente se presente en la mayor parte del país.

Ante el embate de las tendencias globales y de cara a su limitada capacidad de intervención, los principales retos que en materia de desarrollo urbano enfrentan 
los gobiernos municipales son la urgencia por modificar estos patrones de urbanización, fomentar los procesos de densificación y fomentar la coordinación metropolitana entre los distintos órdenes de gobierno.

Desde esa perspectiva, evidentemente la gestión pública carece de eficiencia, pues no regula en forma satisfactoria los frecuentes conflictos que en la construcción del espacio habitable surgen entre el interés público y el privado. Por lo tanto, la necesidad de evaluar el modo en que se realiza la gestión del proceso de urbanización aparece como una tarea impostergable, con el propósito de detectar, y resolver en su caso, los pequeños escollos que evitan el cabal desempeño de la función correspondiente a cada nivel de gobierno.

El modelo institucional vigente en México se diseñó para un gobierno dotado de competencias y con capacidad de dirección para determinar y encabezar el rumbo de la sociedad. Empero, una serie de circunstancias cambiaron notablemente el panorama. Las crisis económicas mostraron los excesos de la intervención gubernamental en países con inmadurez en el conjunto de agencias que conforman el aparato de gobierno. En respuesta a ello, se recortó la vertiente social del Estado y se estimuló la inversión privada aun en áreas de alta sensibilidad sin reservar suficientes instrumentos de regulación. El nuevo escenario mostró la limitación de las políticas estatales para estimular el crecimiento económico. Adicionalmente, influyentes segmentos de la sociedad demandan la participación de nuevos actores en la definición del tipo de país, además de nuevas capacidades para definir escenarios que sólo la conjunción del esfuerzo colectivo puede lograr. En conjunto, estas transformaciones evidenciaron la pérdida de capacidad de gestión del Estado, en forma similar a lo ocurrido en todo el mundo.

Esta nueva situación plantea dos alternativas para los gobiernos locales. La primera consiste en apelar a la voluntad de los partidos políticos solicitando el acuerdo para una verdadera Reforma Política, entre cuyos temas pueden mencionarse: la división de poderes, sus facultades, la supervisión de sus actividades y los mecanismos de dimisión; la federación y las atribuciones de los gobiernos federal, estatales y municipales en los terrenos fiscal, político y regulatorio; una nueva Constitución; el nombramiento, atribuciones y obligaciones de un jefe de gobierno, en vez de un presidente; el sistema de partidos políticos, su financiamiento, las candidaturas independientes, la reelección en el poder legislativo y la revocación del mandato; el sistema judicial independiente del poder ejecutivo. Este nuevo contrato social podría favorecer la gestión pública.

Empero, considerando que la primera alternativa es inviable en el corto plazo, para los gobiernos locales, conscientes de que su función es impulsar el desarrollo de la población que alberga su territorio, quizás una respuesta inmediata sea la creación de comités consultivos en los cuales la representación de las agencias involucradas en decisiones relevantes de desarrollo urbano se enriquezcan con la participación de asociaciones de residentes, académicos y empresarios, bajo la perspectiva de establecer un sistema de arreglos institucionales entre los distintos órdenes de gobierno que confluyen en un espacio metropolitano. 
Finalmente, es preciso subrayar que la única posición no recomendable para un gobierno local es la inmovilidad ante una situación que rebasa su comprensión y sus posibilidades de acción, pues adoptar una actitud pasiva lo condena a aplicar políticas públicas sabiendo que actúa en perjuicio de quienes lo eligieron. IEURE

\section{Referencias bibliográficas}

Acuña, B. \& Graizbord B. (1999). Movilidad cotidiana de trabajadores en el ámbito megalopolitano de la Ciudad de México. En B. Ramírez y J. Delgado (Eds.). Transiciones, Tomo I Territorio y cultura en la Ciudad de México. México: Universidad Autónoma Metropolitana-Plaza y Valdés.

Aguilar, A. G. (2002). Las megaciudades y las periferias expandidas. Ampliando el concepto en Ciudad de México. EURE [online]. Vol. 28, nº 85, pp. 121-149. Consulta electrónica: "http://www.scielo.cl/scielo.php?script=sci_arttext\&pid=S025071612002008500007\&lng=es\&nrm=iso\%3e.\%20ISSN\%200250-7161"

BBVA Bancomer (2008). Situación inmobiliaria en México. México: Servicio de Estudios Económicos. Cabrero, E. (2005). Acción pública y desarrollo local. México: Fondo de Cultura Económica.

Cabrero, E. (1996). Tendencias financieras y estrategias innovadoras en las haciendas municipales. Una aproximación metodológica para su estudio. En: E. Cabrero (Ed.) Los dilemas de la modernización municipal. Estudios sobre la gestión hacendaria en municipios urbanos de México. México: CIDE Miguel Angel Porrúa.

Comisión Nacional de Vivienda (CONAVI), Estadística Nacional de Vivienda. En: "http://www. conafovi.gob.mx/".

Congreso de la Unión (1917). Constitución Politica de los Estados Unidos Mexicanos. En: "http://www. cddhcu.gob.mx/leyinfo". Consulta mayo 14 de 2009.

Congreso del Estado de México (2001). Constitución Politica del Estado Libre y Soberano de México. En: "http://www.cddiputados.gob.mx/POLEMEX/\%20POLEMEX.HTML".

Congreso del Estado de México (2007). Ley de planeación del Estado de México y Municipios. En: "http://www.cddiputados.gob.mx/POLEMEX/POLEMEX.HTML".

Congreso del Estado de México (2008). Ley Orgánica de la Administración Pública del Estado de México. En: "http://www.cddiputados.gob.mx/POLEMEX/POLEMEX.HTML".

Congreso del Estado de México (2009a). Ley Orgánica Municipal del Estado de México. En: "http:// www.cddiputados.gob.mx/POLEMEX/POLEMEX.HTML".

Congreso del Estado de México (2009b). Ley de Vivienda del Estado de México. En: "http://www. cddiputados.gob.mx/POLEMEX/POLEMEX.HTML".

Connolly, P. (1988). Crecimiento urbano, densidad de población y mercado inmobiliario. Revista A, vol. IX, nº 25, UAM Azcapotzalco, México.

Connolly, P. (2005). El mercado habitacional. En R. Coulomb (Ed.) La vivienda en el Distrito Federal. Retos actuales y nuevos desafios. México: Instituto de Vivienda del DF, Comisión Nacional de Fomento a la Vivienda y UAM Azcapotzalco.

Covarrubias, F. (2000). Crecimiento Metropolitano de la Ciudad de México y Necesidades de Financiamiento. X Seminario de Economía Urbana y Regional, Instituto de investigaciones Económicas de la UNAM, México. En: "http://www.iiec.unam.mx/actividades/seminarios/seminario_\%20economia_urbana_regional/seminario_economia_urbana_regional_2000.htm” 
De Mattos, C. (2006). Modernización capitalista y transformación metropolitana en América Latina: cinco tendencias constitutivas. América Latina: cidade, campo e turismo, Consejo Latinoamericano de ciencias sociales (CLACSO), San Pablo, diciembre.

Diario Oficial de la Federación (febrero 3, 1983). Decreto por el que se reforma y adiciona el articulo 115 de la Constitución Politica de los Estados Unidos Mexicanos. EN: "http://dof.gob.mx/ nota_to_imagen_fs.php?cod_diario=2063698pagina"

Diario Oficial de la Federación (octubre 2, 2009). Decreto por el que se aprueba el Programa Nacional para la Prevención y Gestión Integral de los Residuos 2009-2012. En: "http://dof.gob.mx/ nota_detalle.php?codigo $=5112599 \&$ fecha $=02 / 10 / 2009 "$

Duhau, E. \& Cruz, M. S. (2006). Suelo para Vivienda. En R. Coulomb y M. Schteingart (Eds.). Entre el Estado y el mercado. La vivienda en el México de hoy. México: Miguel Ángel PorrúaUniversidad Autónoma Metropolitana, Azcapotzalco.

Duhau, E. (1998). Hábitat popular y politica urbana. México: Miguel Ángel Porrúa-Universidad Autónoma Metropolitana.

Gaceta Oficial del Distrito Federal (1994). Estatuto de Gobierno del Distrito Federal.

Girón, A. \& Chapoy, A. (2009). Financiarización y titulización: un momento Minsky. Economía$U N A M$, Vol. $6 \mathrm{n}^{\circ} 16$, pp 44-56.

Gobierno del Distrito Federal- Fideicomiso para el Mejoramiento de las Vías de Comunicación del Distrito Federal (FIMEVIC) sf, Problemas de movilidad en la Ciudad de México, recuperado el 4 de agosto de 2008, de: "http://www.fimevic.df.gob.mx/problemas/1diagnostico.htm".

Gobierno del Estado de México, Secretaría de Desarrollo Urbano, consulta electrónica: "http://www. edomex.gob.mx/sedur/estadisticas/conjuntos-urbanos".

Graizbord, B. \& Santillán, M. (2005). Dinámica demográfica y generación de viajes al trabajo en el AUCM: 1994-2000. Estudios Demográficos y Urbanos, Vol. 20 n 1, El Colegio de México.

Guillén T. \& Ziccardi, A. (2004). Introducción: parámetros de la reforma municipal en México. En T. Guillén y A. Ziccardi (Eds.). Innovación y continuidad del municipio mexicano. Análisis de la reforma municipal de 13 Estados de la República. México: UNAM-Miguel Ángel Porrúa.

INEGI (2005). II Conteo de Población y Vivienda 2005.

INEGI (2000). Muestra Censal del XI Censo General de Población y Vivienda 2000.

INEGI-GDF-Gobierno del Estado de México (2007). Encuesta Origen-Destino de la Zona Metropolitana del Valle de México.

Islas, V. (2004) Llegando tarde al compromiso: la crisis del transporte en la Ciudad de México. México: El Colegio de México.

Isunza, G. \& Soriano, V. (2007). Mercado de trabajo y movilidad en la Ciudad de México. Mundo Siglo $X X I, \mathrm{n}^{\circ} 11$, invierno, IPN-CIECAS, México, pp 45-56.

Isunza, G. (2010). Política de Vivienda y Movilidad Residencial en la Ciudad de México. Estudios Demográficos y Urbanos 74, Vol. 25, n² 2, pp. 277-316, El Colegio de México.

López, T. S. (2008). Los intermediarios financieros no bancarios en México. ¿Fuentes de financiamiento o generadores de inestabilidad financiera? El caso de las Sociedades Financieras de Objeto Múltiple. Economía Informa $\mathrm{n}^{\circ}$ 355, noviembre-diciembre, UNAM.

Monclús, F. J. (1998). Suburbanización y nuevas periferias. Perspectivas geográfico-urbanísticas. En F. J. Monclús (Ed.). La ciudad dispersa. Barcelona: Centre de Cultura Contemporània de Barcelona. 
Organización para la Cooperación y el Desarrollo Económico (OCDE) (1997). La transformación de la gestión pública. Las reformas en los paises de la Organización para la Cooperación y el Desarrollo Económico (OCDE). Madrid: Ministerio de Administraciones Públicas, Secretaría General Técnica y Ministerio de la Presidencia. Boletín Oficial del Estado.

Reporte Índigo (2010). Vídeo Todos los caminos llevan a Peña Nieto. En: "http://www.youtube.com/ watch?v=ondJGHovOvw".

Rojo, P. (2009). Financiamiento para los municipios 2010 ¿Tranquilidad o preocupación? Premio Gobierno y Gestión Local. Centro de Investigación y Docencia Económicas (CIDE). En: "http://www.premiomunicipal.org.mx/p2009/articulos.php".

Secretaría de Desarrollo Urbano (2006). Planes Municipales de Desarrollo Urbano. México: Gobierno del Estado de México. "http://.www.edomex.gob.mx/sedur/planes-de-desarrollo/municipales"

Secretaría de Gobernación (2007). Catálogo de Programas Federales para los Municipios. México. En: "http://www.e-local.gob.mx/wb2/INAFED2006/INAF_Pub_linea".

SEDESOL-CONAPO-INEGI (2005). Delimitación de las zonas metropolitanas de México.Incluye 16 delegaciones del Distrito Federal, 58 municipios del Estado de México y un municipio del Estado de Hidalgo, según la delimitación de la Secretaría de Desarrollo Social (SEDESOL), el Consejo Nacional de Población (CONAPO) y el INEGI, 2005. 